\title{
Simultaneous observations of large-scale traveling ionospheric disturbances on the nightside and dayside middle latitude
}

\author{
H. T. Cai, F. Yin, S. Y. Ma, J. S. Xu, and Y. W. Liu \\ Department of Space Physics, School of Electronic Information, Wuhan University, Wuhan, 430072, China \\ Key Laboratory of Geospace Environment and Geodesy, Ministry of Education of PRC, Wuhan, 430072, China \\ Correspondence to: H. T. Cai (htcai@whu.edu.cn)
}

Received: 7 June 2012 - Revised: 13 November 2012 - Accepted: 2 December 2012 - Published: 19 December 2012

\begin{abstract}
In this paper, we present further observational evidence for the transpolar propagation of large-scale traveling ionospheric disturbances (LSTIDs) from their nightside source region to the dayside reported by Cai et al. (2011). Slant total electron content (STEC) observed by longitudinally aligned GPS receiver chains in North American and European sectors was analyzed to demonstrate presences of LSTIDs at both nightside and dayside mid-latitude. Signatures of TID were inferred from phase difference in time series of STEC perturbations (TECP) derived from measurements of ground-based GPS receivers, which are separated by hundreds of kilometers longitudinally. Periods of the daytime and nighttime ionospheric disturbances were estimated to be around $128 \mathrm{~min}$, being in good agreement with that of the transpolar AGW (atmospheric gravity wave) recorded by EISCAT (European Incoherent Scatter Scientific Association)/ESR (EISCAT Svalbard Radar) radars. On the dayside, the LSTID moved equatorward with an average phase speed of $\sim 440 \mathrm{~m} \mathrm{~s}^{-1}$. In North American sector, however, southward speed of the nighttime LSTID was much slower, being around $160 \mathrm{~m} \mathrm{~s}^{-1}$. We suggest that the observed daytime and nighttime mid-latitude LSTIDs are likely to have the same source region, being located somewhere at nighttime auroral latitude. Having been launched on the nightside, the waves propagate simultaneously equatorward and poleward. The equatorward-moving waves are recorded by GPS receiver chain in North American sector. The polewardmoving waves, however, cross the polar cap from nightside to dayside and then are detected consecutively at high and midlatitudes by EISCAT/ESR radars and GPS receiver chains, respectively.
\end{abstract}

Keywords. Ionosphere (Ionosphere-atmosphere interactions; Mid-latitude ionosphere; Wave propagation)

\section{Introduction}

Properties of the traveling ionospheric disturbances (TIDs) have been investigated extensively recently by means of observations and numerical simulation (as reviewed by Hocke and Schlegel, 1996, and references therein). It is now widely accepted that TIDs are the ionospheric manifestations of atmospheric gravity waves (AGW) since the landmark paper of Hines (1960). In general, TIDs with periods of $1 \mathrm{~h}$, wavelengths of about $1000 \mathrm{~km}$, and horizontal speeds greater than $250 \mathrm{~m} \mathrm{~s}^{-1}$ are referred to as large-scale ones (Hunsucker, 1982). Davis (1971) provided strong support for the contention that large-scale TIDs (LSTIDs) originate during polar substorms. LSTIDs are usually expected to have been launched at auroral or subauroral latitudes during substorm conditions, as a result of Joule heating and Lorentz forces.

It was demonstrated that LSTIDs were capable of propagating for thousands of kilometers without significant attenuation (Francis, 1975). The simultaneous presence of TIDs at high, mid- and low latitudes, and in both Northern and Southern Hemispheres, propagating from both auroral regions toward the geographic Equator, was detected during magnetically disturbed periods (Valladares et al., 2009). Richmond (1978) argued that, according to classical gravity-wave theory, gravity waves with a point source would result in an isotropically propagating disturbance. Recently, storm time LSTIDs propagating equatorward of the auroral region have been detected extensively (e.g. Williams et al., 1993, and reference therein, Shiokawa et al., 2007; Ding et al., 2008; Valladares et al., 2009).

With the help of a fully coupled thermosphereionosphere-plasmasphere model, Balthazor and Moffett (1999) investigated the morphology of large-scale TIDs 
propagating poleward from auroral sources and claimed that poleward-propagation of large-scale traveling atmospheric disturbances could be self-consistently driven by enhancements in auroral heating. TIDs propagating simultaneously both northward and southward from a source have ever been inferred from ionosonde data (Morgan, 1983). Bowman and Mortimer (2010) suggested that LSTIDs have the ability to encircle the Earth, which implies that transpolar propagation of LSTID would be expected.

With ground-based EISCAT (European Incoherent Scatter Scientific Association)/ESR (EISCAT Svalbard Radar) radar observations, Cai et al. (2011) reported a case study of the characteristics of AGW/TID within the dayside polar cap. The authors suggested that the disturbance had propagated across the northern polar cap from the nighttime auroral source during substorm conditions. However, they did not provide any observational evidence to support their hypothesis. If the AGW/TID were actually launched on the nightside auroral latitude, measurable signatures of the equatorwardpropagating wave might be expected equatorward of the source region at nightside. This paper contributes further support for the hypothesis of Cai et al. (2011), focusing on propagations of the induced LSTID from the same source on both nightside and dayside mid-latitude. Dataset and method employed in present paper are introduced in Sect. 2. In Sect. 3, observations of LSTIDs on both nightside and dayside are summarized, as well as geomagnetic conditions. Comparisons and brief discussion are presented in Sect. 4. Summary is following in Sect. 5.

\section{Data and method}

Our primary dataset consists of slant total electron content (STEC) values measured by GPS receivers that routinely operate in North American and European sectors. The International GNSS Service (IGS) provides GPS RINEX files, which are available on the web site of http://sopac.ucsd.edu. The STEC observed by a GPS receiver-satellite pair can be derived from carrier phase advance and group delays recorded in the RINEX files. Resolution of the STEC time series is $30 \mathrm{~s}$.

Assume that the STEC series observed by a GPS receiversatellite pair consists of three parts: $\mathrm{STEC}_{0}$, which represents the background trends of STEC; STEC $_{\mathrm{p}}$, which reflects the TEC perturbations caused by TIDs; and the satellite and receiver instrumental biases, $B_{\mathrm{s}}$ and $B_{\mathrm{r}}$. We have

$\mathrm{STEC}=\mathrm{STEC}_{0}+\mathrm{STEC}_{\mathrm{p}}+B_{\mathrm{s}}+B_{\mathrm{r}}$.

The background trend $\mathrm{STEC}_{0}$ can be estimated with various algorithms. Running average has been used by a number of authors, with a time widow ranging from $1 \mathrm{~h}$ to several hours (e.g. Nicolls et al., 2004; Shiokawa et al., 2002). Ding et al. (2008) and Valladares et al. (2009) calculated the unperturbed TEC values by means of fitting method. In this paper, in order to precisely keep the phase information of ionospheric perturbations, the STEC curves corresponding to each satellite pass and for each GPS receiver were detrended by means of zero-phase digital filtering (Butterworth type). A four-order low-pass Butterworth filter was designed to allow variations with periods longer than $3 \mathrm{~h}$ to pass through, since Hocke (1996) suggested that time scales with period $>2.5-$ $3 \mathrm{~h}$ could be associated with tidal modes. The satellite and receiver instrumental biases, $B_{\mathrm{S}}$ and $B_{\mathrm{r}}$, are quite stable during a satellite pass (Hernández-Pajares et al., 1997). Thus, these instrumental biases are not included in the resulted TECP (time series of STEC perturbations), which only contains the disturbances of STEC along the propagation path.

In order to eliminate disturbances introduced by multipath propagation of the carrier signal, only the STEC series with elevation higher than $40^{\circ}$ were included in our study. It has been suggested that higher values of the elevation angle correspond to more reliable TID structures and dynamics (Afraimovich et al., 2000). The horizontal observation range of the ground-based GPS receiver will be narrowed if higher elevation cutoff is used. Higher elevation cutoff $\left(\sim 60^{\circ}\right)$ was chosen for studies in the region with a relatively denser distribution of GPS receivers (e.g. Saito et al., 1998; Tsugawa et al., 2003). For most GPS receivers mentioned in the following sections, the elevation cutoff adopted in our study generally leaves an original STEC time series of about $4 \mathrm{~h}$, which is long enough to contain at least one cycle of ionospheric disturbance of a typical LSTID (Ding et al., 2008).

The presence of a LSTID is identified by means of comparing time series of STEC perturbations derived from measurements observed by a ground-based receiver chain during a GPS satellite pass. Perturbations of the slant TEC series, rather than those of the derived vertical TEC, were analyzed in order to avoid errors introduced by converting into vertical TEC. Since LSTIDs were observed predominately propagating equatorward from high latitudes (e.g. Hunsucker, 1982; Shiokawa et al., 2007; Ding et al., 2008), in this paper the ground-based GPS receiver chains have been chosen such that they are longitudinally aligned as much as possible. If a LSTID field were passing by, periodic fluctuations with phase progression along the GPS receiver chain would be expected in time series of the TECP. The propagation properties of the LSTID, such as period and horizontal phase speed, can be estimated from the TECP temporal variations and the phase differences between the GPS receivers accordingly. This is different than the method adopted by many authors in recent publications (e.g. Saito et al., 1998; Nicolls et al., 2004; Ding et al., 2008; Valladares et al., 2009), who identified the LSTID and evaluated its properties from a series of two-dimensional TECP maps. Although Saito et al. (1998) warned that the phase differences of the TECP might be biased by spatial variations, we claim that our method is reliable for TID signatures identification, provided that enough proper ground-based GPS stations are available. In present 

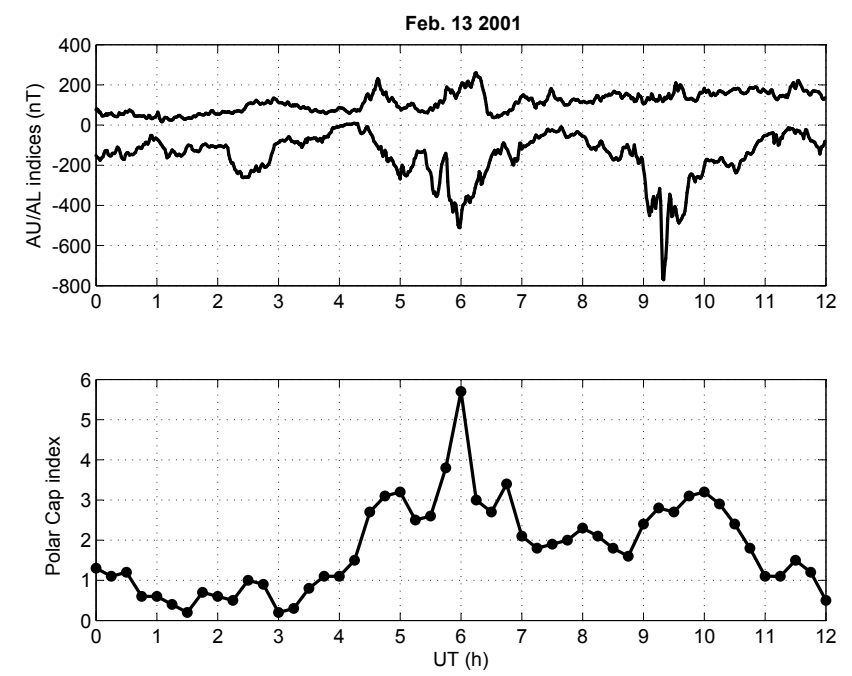

Fig. 1. AU/AL indices from WDC (World Data Center) for Geomagnetism, Kyoto (top panel), and polar cap index from WDC for Geomagnetism, Copenhagen (bottom panel), during the interval 00:00-12:00 UT on 13 February 2001.

study, each GPS receiver chain is composed of 12 or more ground-based stations, covering at least $10^{\circ}$ in latitude.

\section{Observations}

\subsection{Geomagnetic activity}

The Kp index varied between $4+$ and 3 during 13 February 2001, suggesting moderate geomagnetic activity. The AU/AL and polar cap indices during the time interval of interest are shown in Fig. 1. It can be noted that $\mathrm{AL}$ index exhibited three negative peaks around 02:20, 06:00 and 09:20 UT respectively, indicating temporal enhancements in the strength of the westward electrojet. The polar cap index varied somewhat during the interval, with its magnitude being generally lower than 4 except for an enhancement to $p=5.7$ near 06:00 UT.

\subsection{Observations of LSTID on the dayside}

The left-hand panel of Fig. 2 shows time series of TECP derived from the STEC observed by a GPS receiver chain and the GPS satellite PRN 30 from 10:00 to 14:00 UT on 13 February 2001. In order to avoid overlapping, the TECP series have been offset by 3 TEC units (TECU). The fourcharacter station codes of these GPS stations are also listed in the panel. The GPS receiver chain consists of 12 groundbased stations approximately longitudinally aligned around $27^{\circ} \mathrm{E}(\mathrm{LT} \approx \mathrm{UT}+1.8 \mathrm{~h}$ ), among which the average latitudinal distance is several hundred kilometers. The geographic locations of these GPS receivers are listed in the right-hand side of Table 1.
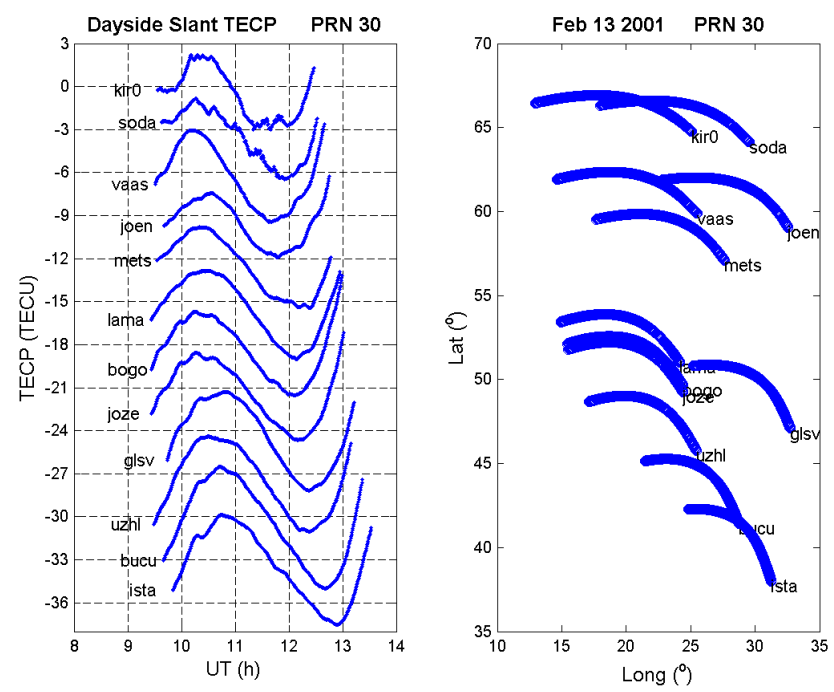

Fig. 2. Time series of the slant TEC perturbations (TECP) derived from measurements observed by the GPS satellite PRN 30 and a ground-based GPS receiver chain, which are close to being longitudinally aligned around $27^{\circ} \mathrm{E}(\mathrm{LT} \approx \mathrm{UT}+1.8 \mathrm{~h}$ ) (the left-hand panel). These slant TECP series have been offset by 3 TECU to avoid overlapping. The right-hand panel shows the spatial variations of the ionospheric pierce points (at $350 \mathrm{~km}$ ) for all the GPS satellite-receiver pairs.

Table 1. Geographic locations of the two ground-based GPS receiver chains on the dayside.

\begin{tabular}{llll}
\hline $\begin{array}{l}\text { Site } \\
\text { code }\end{array}$ & $\begin{array}{l}\text { Geographical latitude } \\
\text { and longitude }\end{array}$ & $\begin{array}{l}\text { Site } \\
\text { code }\end{array}$ & $\begin{array}{l}\text { Geographical latitude } \\
\text { and longitude }\end{array}$ \\
\hline trom & $69.54^{\circ} \mathrm{N}, 18.94^{\circ} \mathrm{E}$ & kir0 & $67.74^{\circ} \mathrm{N}, 21.06^{\circ} \mathrm{E}$ \\
kiru & $67.72^{\circ} \mathrm{N}, 20.97^{\circ} \mathrm{E}$ & soda & $67.28^{\circ} \mathrm{N}, 26.39^{\circ} \mathrm{E}$ \\
vil0 & $64.55^{\circ} \mathrm{N}, 16.56^{\circ} \mathrm{E}$ & vaas & $62.81^{\circ} \mathrm{N}, 21.77^{\circ} \mathrm{E}$ \\
vis0 & $57.48^{\circ} \mathrm{N}, 18.37^{\circ} \mathrm{E}$ & joen & $62.23^{\circ} \mathrm{N}, 30.10^{\circ} \mathrm{E}$ \\
helg & $53.99^{\circ} \mathrm{N}, 7.89^{\circ} \mathrm{E}$ & mets & $60.05^{\circ} \mathrm{N}, 24.40^{\circ} \mathrm{E}$ \\
wsrt & $52.73^{\circ} \mathrm{N}, 6.60^{\circ} \mathrm{E}$ & lama & $53.71^{\circ} \mathrm{N}, 20.67^{\circ} \mathrm{E}$ \\
kosg & $51.99^{\circ} \mathrm{N}, 5.81^{\circ} \mathrm{E}$ & bogo & $52.29^{\circ} \mathrm{N}, 21.04^{\circ} \mathrm{E}$ \\
wroc & $50.93^{\circ} \mathrm{N}, 17.06^{\circ} \mathrm{E}$ & joze & $51.91^{\circ} \mathrm{N}, 21.03^{\circ} \mathrm{E}$ \\
eusk & $50.49^{\circ} \mathrm{N}, 6.76^{\circ} \mathrm{E}$ & glsv & $50.18^{\circ} \mathrm{N}, 30.50^{\circ} \mathrm{E}$ \\
klop & $50.03^{\circ} \mathrm{N}, 8.73^{\circ} \mathrm{E}$ & uzhl & $48.44^{\circ} \mathrm{N}, 22.30^{\circ} \mathrm{E}$ \\
gope & $49.72^{\circ} \mathrm{N}, 14.79^{\circ} \mathrm{E}$ & bucu & $44.27^{\circ} \mathrm{N}, 26.13^{\circ} \mathrm{E}$ \\
wtzr & $48.95^{\circ} \mathrm{N}, 12.88^{\circ} \mathrm{E}$ & ista & $40.91^{\circ} \mathrm{N}, 29.02^{\circ} \mathrm{E}$ \\
wien & $48.03^{\circ} \mathrm{N}, 16.37^{\circ} \mathrm{E}$ & & \\
rtmn & $47.33^{\circ} \mathrm{N}, 14.34^{\circ} \mathrm{E}$ & & \\
grab & $46.88^{\circ} \mathrm{N}, 15.49^{\circ} \mathrm{E}$ & & \\
ajac & $41.74^{\circ} \mathrm{N}, 8.76^{\circ} \mathrm{E}$ & & \\
\hline
\end{tabular}

In the left-hand panel of Fig. 2, clear periodic fluctuations can be noted in the time series of TECP observed at all ground-based GPS stations. The temporal variations of these TECP observed by the GPS receiver chain exhibit a high level of coherence during the plotted interval, from the auroral latitude $\left(67.4^{\circ} \mathrm{N}\right)$ down to mid-latitude region $\left(40.9^{\circ} \mathrm{N}\right)$. 

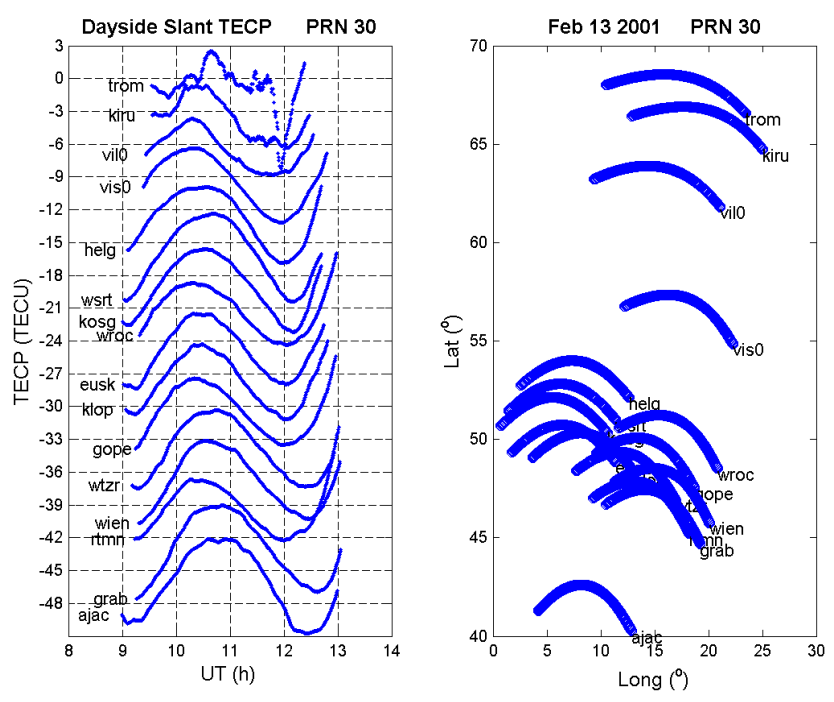

Fig. 3. The same as Fig. 2 but for the ground-based GPS receiver chain around $16^{\circ} \mathrm{E}(\mathrm{LT} \approx \mathrm{UT}+1 \mathrm{~h})$. The displayed slant TECP series have been offset by 3 TECU in the left-hand panel to avoid overlapping.

The coherence suggests a clear linkage between the disturbances of the integrated electron density detected at various stations in a rather broad latitudinal range $\left(\sim 26^{\circ}\right)$. Phase differences can be figured out by comparing the peak-to-peak variations of the TECP fluctuations. The latitudinal displacements of the ionospheric pierce points (IPPs) of the satellitereceiver paths produce a time lag of several minutes between the neighboring stations, implying a clear picture of an equatorward phase progression of the ionospheric disturbances. Spectral analysis of these TECP series suggests a central period of $128 \mathrm{~min}$ for the TID. The apparent phase velocity between the GPS receiver stations was evaluated by means of maximum entropy cross-spectral analysis method reported by Ma et al. (1998). The equatorward phase speed of the TID has been estimated to be $440 \mathrm{~m} \mathrm{~s}^{-1}$. This value was obtained by averaging the phase velocities between the neighboring stations in Fig. 2. The propagation characteristics suggest the presence of a large-scale TID (Hunsucker, 1982).

Geographical latitudes and longitudes of the IPPs for the GPS satellite-receiver paths are sketched in the right-hand panel of Fig. 2. The IPPs have been calculated with the assumption that average peak height of the ionospheric $F_{2}$ layer is at $350 \mathrm{~km}$. Because of the movement of the GPS satellite, the horizontal location of the IPPs varied somewhat. During the plotted interval in Fig. 2, these IPPs generally have a latitudinal range of $2-4^{\circ}$ and a longitudinal range of $\sim 10^{\circ}$. This is the main reason why Saito et al. (1998) warned that temporal and/or spatial variations of the ionospheric plasma might contribute to the phase differences between the TECP series observed at neighboring GPS stations. Recently, effects on GPS measurements caused by mediumscale TIDs have been investigated in detail by Hernández-
Pajares et al. (2006), based on a database of near one solar cycle and four local networks in the Northern and Southern Hemispheres. According to their results, Hernández-Pajares and co-authors concluded that the movement of the IPPs can have some but not significant influence on the estimation of the velocity and frequency of a TID. At an altitude of $350 \mathrm{~km}$, a typical value of the ionospheric piece point velocity is about $60-70 \mathrm{~m} \mathrm{~s}^{-1}$, which is an order smaller than the estimated equatorward phase speed of the LSTID in our case. Hence, it seems that the spatial variations of the ionospheric electron density have relatively little contribution to phase differences of the observed TID.

The passage of the large-scale TID on the dayside has also been detected by other GPS satellite-receiver pairs. Figure 3 shows the TECP series observed by another longitudinally aligned GPS receiver chain around $16^{\circ} \mathrm{E}(\mathrm{LT} \approx \mathrm{UT}+1 \mathrm{~h})$. The geographical latitude and longitude of these GPS stations are listed on the left-hand side of Table 1. The time series of the TECP in the figure have been offset by 3 TECU to avoid overlapping of these curves. In the left-hand panel, similar periodic variations are clear in the series of slant TEC perturbations at most GPS stations. The distortion in waveform of the TECP series at GPS station "trom" was possible due to contamination from other auroral activity. Spectral analysis of these TECP series suggests a similar propagation property to what we inferred from measurements shown in Fig. 2.

The zonal distance between the two meridional groundbased GPS receiver chains is more than $1000 \mathrm{~km}$. Time variations of TECP series displayed in Figs. 2 and 3 are similar and are roughly in phase with each other. We attribute this phenomenon to the passage of a large-scale TID. As the LSTID is propagating southward (equatorward) from high latitude, the ionospheric compressions and rarefactions are seen sequentially in the variability of the integrated electron density over the area of $67-40^{\circ} \mathrm{N}$ latitude and $16-27^{\circ} \mathrm{E}$ longitude.

\subsection{Observations of LSTID on the nightside}

The presence of the LSTID on the nightside was also inferred from comparison of the TECP time series observed at various longitudinally aligned stations. Two meridional GPS receiver chains were chosen in the Northern America sector. Geographic locations of these ground-based GPS receivers are listed in Table 2. The left-hand side of Table 2 contains a group of GPS receivers located around $75^{\circ} \mathrm{W}$ $(\mathrm{LT}=\mathrm{UT}-5 \mathrm{~h})$, whilst the right-hand side consists of 18 receivers around $95^{\circ} \mathrm{W}(\mathrm{LT} \approx \mathrm{UT}-6.3 \mathrm{~h})$. The zonal distance between the two GPS receiver chains is more than $2000 \mathrm{~km}$, and the latitudinal distance between GPS stations in each chain is $\sim 100 \mathrm{~km}$. Satellite passes during the local nighttime have been chosen for analyzing in this section.

The left-hand panel of Fig. 4 depicts time series of the slant TEC perturbations detected at 18 separated GPS 

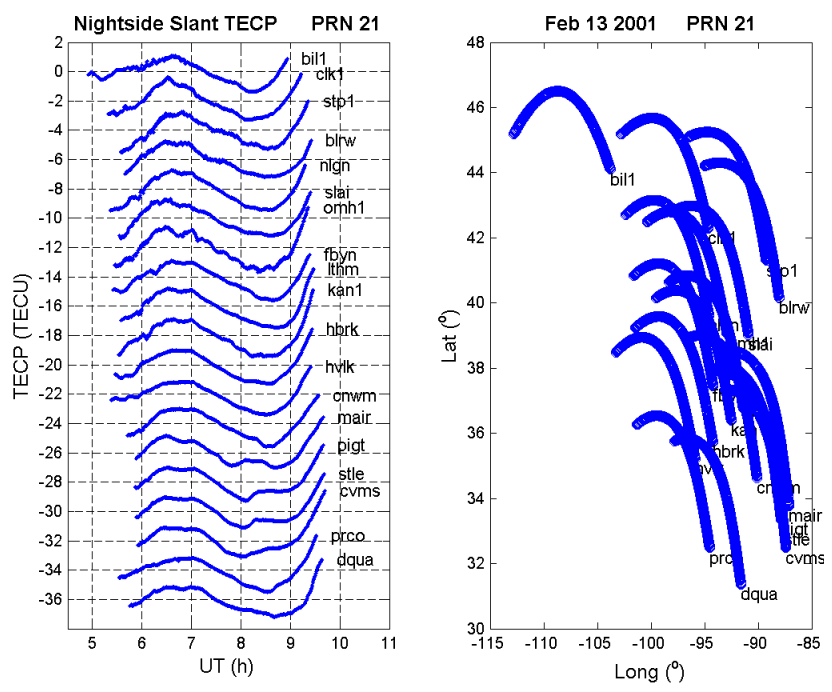

Fig. 4. Time series of slant TEC perturbations (TECP) derived from the paths of the GPS satellite (PRN 21) to various ground-based receivers, which are close to being longitudinally aligned around $95^{\circ} \mathrm{W}(\mathrm{LT} \approx \mathrm{UT}-6.3 \mathrm{~h}$ ) (the left-hand panel). These slant TECP have been offset by 2 TECU to avoid overlapping. The right-hand panel shows latitude time variations of the ionospheric pierce points for all the GPS satellite-receiver paths.

Table 2. Geographic locations of the two ground-based GPS receiver chains on the nightside.

\begin{tabular}{llll}
\hline $\begin{array}{l}\text { Site } \\
\text { code }\end{array}$ & $\begin{array}{l}\text { Geographical latitude } \\
\text { and longitude }\end{array}$ & $\begin{array}{l}\text { Site } \\
\text { code }\end{array}$ & $\begin{array}{l}\text { Geographical latitude } \\
\text { and longitude }\end{array}$ \\
\hline algo & $45.76^{\circ} \mathrm{N}, 78.07^{\circ} \mathrm{W}$ & bil1 & $45.78^{\circ} \mathrm{N}, 108.0^{\circ} \mathrm{W}$ \\
chb1 & $45.46^{\circ} \mathrm{N}, 84.47^{\circ} \mathrm{W}$ & clk1 & $44.74^{\circ} \mathrm{N}, 97.96^{\circ} \mathrm{W}$ \\
cags & $45.39^{\circ} \mathrm{N}, 75.81^{\circ} \mathrm{W}$ & stp1 & $44.11^{\circ} \mathrm{N}, 91.90^{\circ} \mathrm{W}$ \\
pnb1 & $44.26^{\circ} \mathrm{N}, 68.77^{\circ} \mathrm{W}$ & blrw & $43.04^{\circ} \mathrm{N}, 90.53^{\circ} \mathrm{W}$ \\
bru1 & $43.70^{\circ} \mathrm{N}, 69.95^{\circ} \mathrm{W}$ & nlgn & $42.02^{\circ} \mathrm{N}, 97.80^{\circ} \mathrm{W}$ \\
you1 & $43.04^{\circ} \mathrm{N}, 78.97^{\circ} \mathrm{W}$ & slai & $41.71^{\circ} \mathrm{N}, 93.70^{\circ} \mathrm{W}$ \\
sycn & $42.92^{\circ} \mathrm{N}, 76.09^{\circ} \mathrm{W}$ & fbyn & $39.89^{\circ} \mathrm{N}, 97.31^{\circ} \mathrm{W}$ \\
por4 & $42.88^{\circ} \mathrm{N}, 70.71^{\circ} \mathrm{W}$ & lthm & $39.39^{\circ} \mathrm{N}, 94.17^{\circ} \mathrm{W}$ \\
npri & $41.32^{\circ} \mathrm{N}, 71.33^{\circ} \mathrm{W}$ & kan1 & $38.94^{\circ} \mathrm{N}, 95.40^{\circ} \mathrm{W}$ \\
mor1 & $40.60^{\circ} \mathrm{N}, 72.75^{\circ} \mathrm{W}$ & hbrk & $38.12^{\circ} \mathrm{N}, 97.29^{\circ} \mathrm{W}$ \\
shk1 & $40.28^{\circ} \mathrm{N}, 74.01^{\circ} \mathrm{W}$ & hvlk & $37.47^{\circ} \mathrm{N}, 99.11^{\circ} \mathrm{W}$ \\
red1 & $39.37^{\circ} \mathrm{N}, 75.57^{\circ} \mathrm{W}$ & cnwm & $37.34^{\circ} \mathrm{N}, 92.70^{\circ} \mathrm{W}$ \\
hnpt & $38.40^{\circ} \mathrm{N}, 76.13^{\circ} \mathrm{W}$ & mair & $36.66^{\circ} \mathrm{N}, 89.36^{\circ} \mathrm{W}$ \\
duck & $36.00^{\circ} \mathrm{N}, 75.75^{\circ} \mathrm{W}$ & pigt & $36.19^{\circ} \mathrm{N}, 90.18^{\circ} \mathrm{W}$ \\
& & stle & $35.91^{\circ} \mathrm{N}, 89.86^{\circ} \mathrm{W}$ \\
& & cvms & $35.36^{\circ} \mathrm{N}, 89.64^{\circ} \mathrm{W}$ \\
& & prco & $34.80^{\circ} \mathrm{N}, 97.52^{\circ} \mathrm{W}$ \\
& & dqua & $33.93^{\circ} \mathrm{N}, 94.29^{\circ} \mathrm{W}$ \\
\hline
\end{tabular}

stations, which are approximately longitudinally aligned around $95^{\circ} \mathrm{W}(\mathrm{LT} \approx \mathrm{UT}-6.3 \mathrm{~h})$. An offset of 2 TECU was applied on these TECP series. The corresponding latitudinal and longitudinal traces of the IPPs are displayed in the righthand panel. During the plotted time interval, ionospheric piece points of the satellite-receiver path generally have a lat-
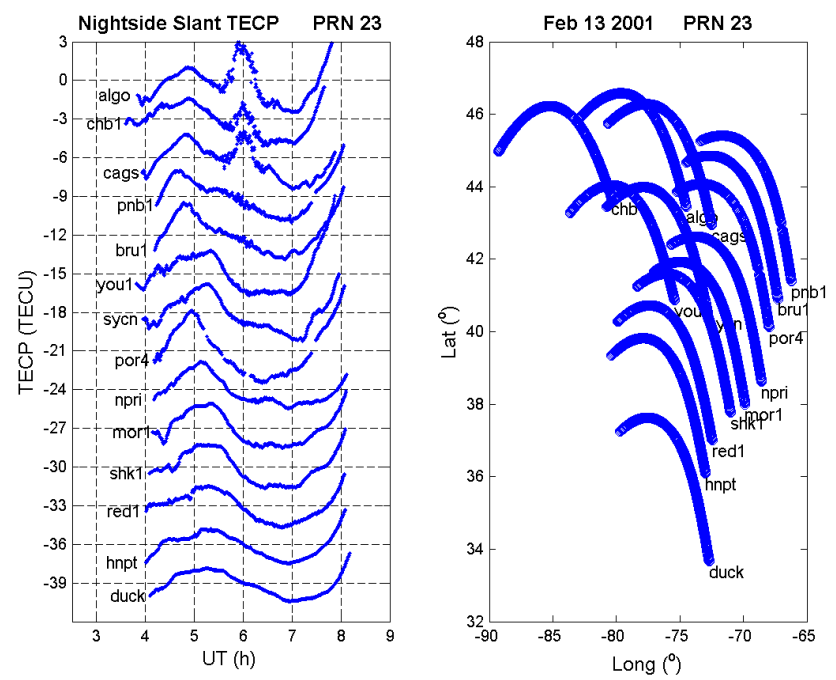

Fig. 5. The same as Fig. 4 but for the ground-based GPS receiver chain around $75^{\circ} \mathrm{W}(\mathrm{LT}=\mathrm{UT}-5 \mathrm{~h})$. The displayed slant TECP series have been offset by 3 TECU in the left-hand panel to avoid overlapping.

itudinal range of $2-4^{\circ}$ and longitudinal range of $\sim 7^{\circ}$. Clear periodic fluctuations of the TECP series can be noted from station "bill" $\left(\sim 46^{\circ} \mathrm{N}\right)$ down to "dqua" $\left(\sim 34^{\circ} \mathrm{N}\right)$. Magnitude of the TECP was $\sim 1$ TECU. Overall, phase progression of the detected ionospheric disturbances was equatorward, which was implied by comparing of the TECP fluctuations at neighboring GPS stations. Spectral analysis of these TECP series suggested a central period of $130 \mathrm{~min}$ for the nighttime ionospheric disturbances, being comparable to what was observed at the dayside. Equatorward phase speed of the nighttime TID was about $160 \mathrm{~m} \mathrm{~s}^{-1}$, rather slower than what was observed in the daytime.

Figure 5 gives another example of the ionospheric disturbances with an equatorward-propagating component on the nightside around $75^{\circ} \mathrm{W}(\mathrm{LT}=\mathrm{UT}-5 \mathrm{~h})$. An offset of 3 TECU was applied on these TECP series in the left panel. The temporal increase of TECP observed at latitudes of $45^{\circ} \mathrm{N}$ (at stations of "algo", "chb1" and "cags") around 06:00 UT must correspond to nighttime geomagnetic activity indicated by the sudden enhancement of the polar cap index (in Fig. 1), which was derived from geomagnetic data obtained at Thule $\left(\sim 70^{\circ} \mathrm{W}\right)$. Phase difference was significant between the TECP fluctuations series detected by the two meridional GPS receiver chains (Figs. 4 and 5), implying that the wavefront of the nighttime LSTID was not longitudinally extended any more at mid-latitudes, but rotated somewhat during its equatorward propagation from high latitudes.

\section{Discussion}

Presence of LSTID in dayside polar region, from $\sim 80^{\circ}$ magnetic latitude to the dayside auroral latitude, has been 

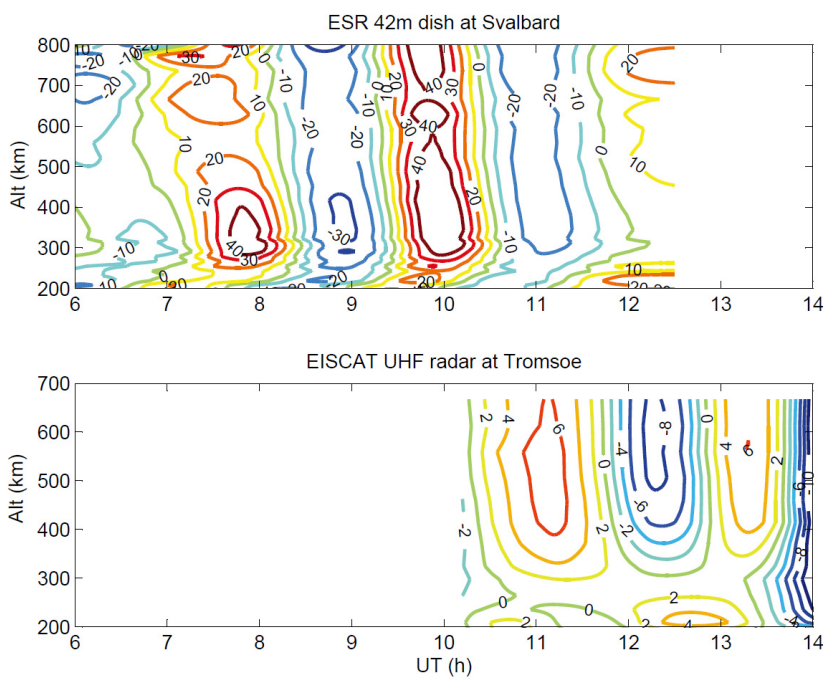

Fig. 6. Fractional electron density fluctuations (in percent) derived from observations of the field-aligned dish of ESR radar at Svalbard $\left(78^{\circ} \mathrm{N}\right.$ Lat) and of the mainland UHF radar at Troms $\emptyset\left(69.6^{\circ} \mathrm{N}\right.$ Lat). The blank periods of 12:30-14:00 UT in the top panel and of 06:00-10:10 UT in the bottom panel are due to unfortunate data gap.

recorded by EISCAT/ESR radars around magnetic local noon (06:00-12:00 UT) on the same day. Signatures of LSTID in electron density probed by EISCAT/ESR radars were described in detail by Cai et al. (2011) and will be only briefly summarized here, as shown in Fig. 6. Fractional electron density fluctuations (in percent), relative to background level, as a function of altitude and time are displayed. The blank periods from 12:30-14:00 UT in the top panel and from 06:0010:10 UT in the bottom panel are due to unfortunate data gap. Clear periodic signatures, as well as inclined wavefronts of the ionization fluctuations, are noted in both panels. By carefully checking on disturbances of electron temperature, ion temperature and ion velocity, Cai and coauthors were convinced that AGWs are responsible for the observed TID, propagating sunward with an average speed of $190 \mathrm{~m} \mathrm{~s}^{-1}$. The period of equatorward-propagating LSTID observed by EISCAT/ESR radar is estimated to be around $120 \mathrm{~min}$.

Figure 7 shows TECP series detected at the dayside and nightside, but for a reference day (12 February 2001). Electrojet activity was quiet in the morning on 12 February 2001, as indicated by the AL/AU indices (not shown here). The TECP series in Fig. 7 were derived by using the same method described in Sect. 2. The left column shows results from the same ground-based GPS receiver chain and the same satellite displayed in Fig. 2, whilst the right column is the same as Fig. 5. It is clear that the coherent wave-like ionospheric disturbances from high latitude to mid-latitude are missing at both dayside (the left column) and nightside (the right column) in the morning of the reference day. This implies that
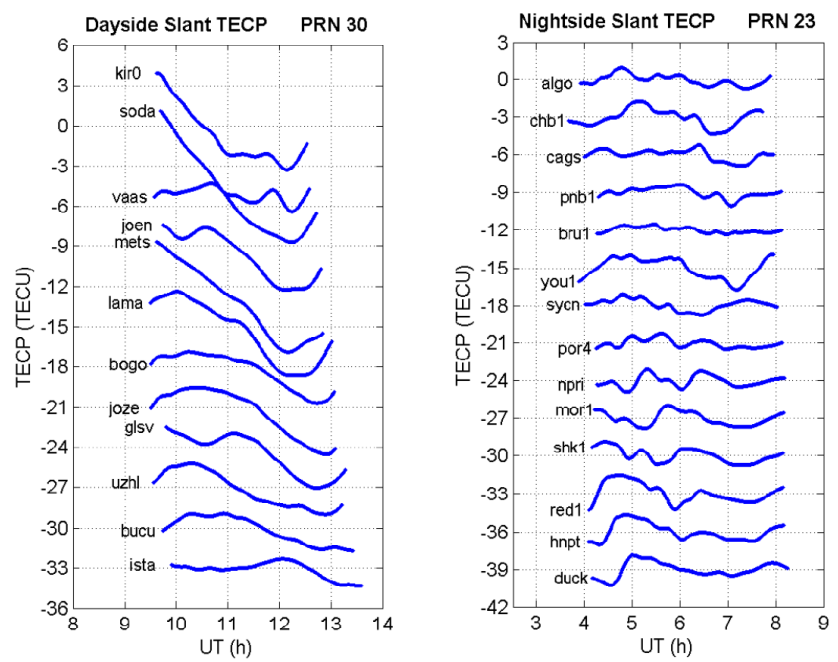

Fig. 7. Time series of slant TEC perturbations (TECP) during the reference day (12 February 2001) derived from the paths of the GPS satellite to the ground-based receiver chains on the dayside (the left column) and on the nightside (the right column). The displayed slant TECP series have been offset by 3 TECU in order to avoid overlapping.

the wave-like structures in ionospheric disturbances detected in our case must be driven by some physical processes.

The top panels of Fig. 8 show spectral analysis results of TECP series derived at dayside and nightside, respectively. For comparison, results for electron density around F2-peak detected by radars at Svalbard and Troms $\varnothing$ are also displayed in the bottom panels. Only 4-h periods of radar observations (07:00-11:00 UT for ESR radar and 10:00-14:00 UT for EISCAT mainland UHF (ultra-high frequency) radar) were input for spectral analysis in order to be comparable with the results of GPS measurements. It can be seen that there is a predominated peak in frequency spectrum, corresponding to a central period of $128 \mathrm{~min}$, for perturbations of both GPS measurements and radar observations, suggesting some close connection between them. By careful comparison of the power spectral density in the top and bottom panels, one may also find out that power spectral density of TECP series decays much more slowly than that of electron density perturbations detected by radars. This implies that TECP series also contain non-neglected variations with periods around the central period. It sounds reasonable since the TECP series are derived from integrated electron density along the path of a satellite-receiver pair and the satellites are moving. By comparing the waves seen by radars (Fig. 6) and these detected by GPS receiver chains at the dayside (Figs. 2 and 3), it seems likely that the presence of LSTID at dayside mid-latitudes is the consequence of the AGW detected in polar region as it continues propagating equatorward.

During this period, the oblique ESR $32 \mathrm{~m}$ dish was directing toward the geomagnetic pole at low elevation $\left(30^{\circ}\right)$. Periodic positive/negative electron density perturbations (not 

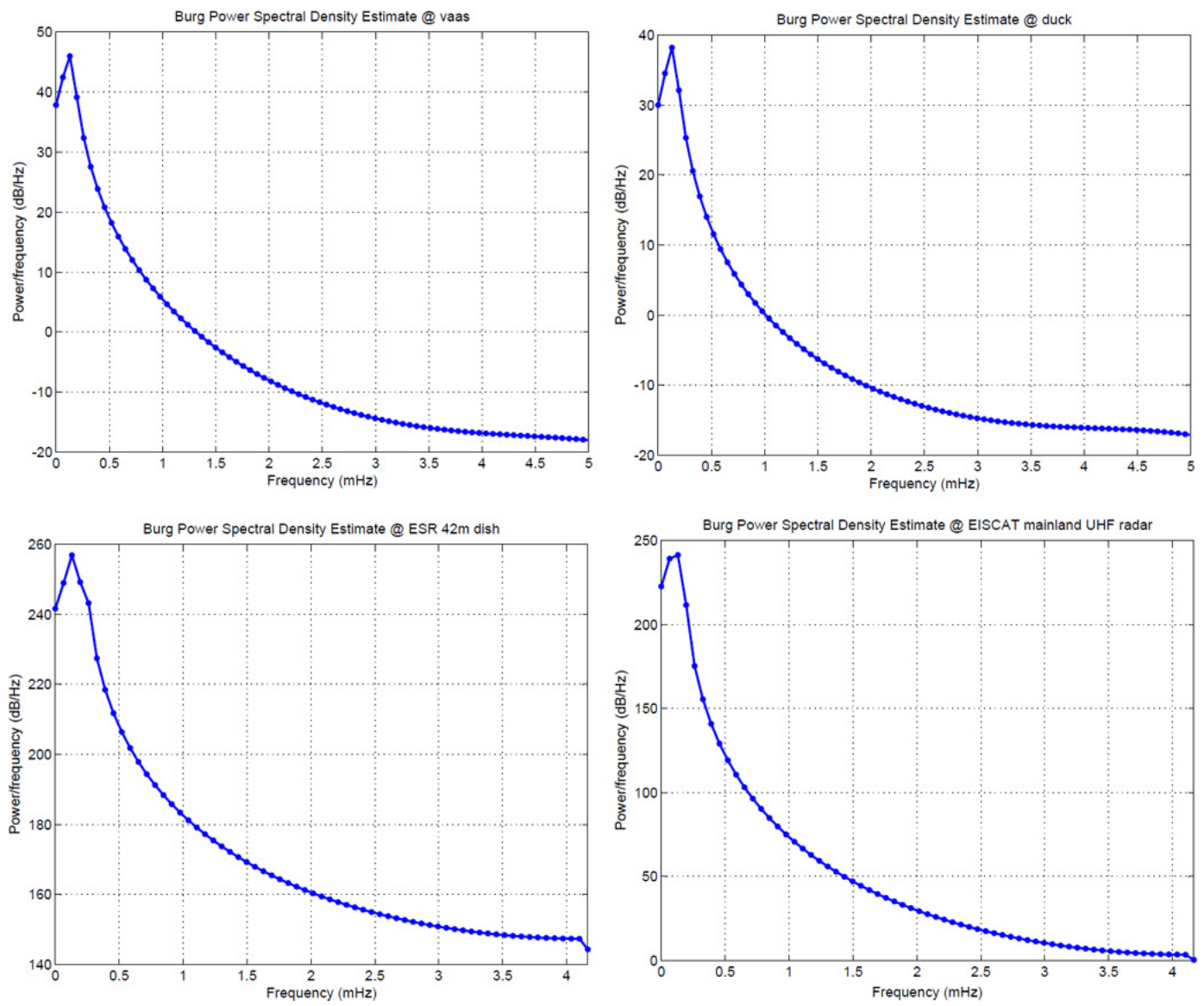

Fig. 8. Power spectral density (PSD) estimated with Burg method of representative TECP series at the dayside and nightside derived from GPS measurements (top panels) and those of EISCAT/ESR radar observations (bottom panels). See text for details.

shown here) were first detected at higher latitude $\left(\sim 80^{\circ}\right.$ magnetic latitude), propagating gradually to lower latitudes. Since LSTIDs usually have their sources at auroral region in bands narrow in latitude and extended in longitude (Hajkowicz, 1991), Cai et al. (2011) suggested that the observed AGW/TID had been launched on the nightside during substorm activity conditions, and propagated poleward from the source region. The poleward-moving waves crossed the polar cap from nightside to dayside and then were detected consecutively in the polar region (by the ESR first over the polar cap and then in the cusp, and by the mainland UHF radar in the auroral oval) and at mid-latitude region (by ground-based GPS receiver chains). However, Cai et al. (2011) did not provide any observational evidence to support their hypothesis.

According to theoretical study of Richmond (1978), longitudinally extended waves are expected to propagate meridionally at both sides of the LSTID source region. If the source of the transpolar propagating AGW was actually located somewhere at nighttime auroral latitudes, it would be followed by induced ionospheric disturbances detectable at both sides, pole- and equatorward. Due to limitation in available measurements, we failed to provide direct observations for nighttime sunward-moving waves poleward of the source. The LSTID detected at daytime mid-latitude, however, could be regarded as an indication for presence of the polewardmoving branch, which crossed the polar cap from nightside to the dayside and continuously propagated to daytime midlatitudes. The other branch of the disturbance at nightside, propagating southwards, was likely to have been recorded by GPS receivers in Northern America sector. Periods of them are in accordance with what the transpolar AGW inferred from EISCAT/ESR observations. We suggest that presence of the southward-propagating LSTID on the nightside provides strong evidence for the location of the AGW source. The source region is expected to be in shape of a band extended in longitude since mainly pole- and equatorward propagation of the LSTIDs were observed.

Due to limitation in duration of the observations, we could not identify reliable information about the appearance time of the LSTIDs. However, we could examine whether the time when the LSTIDs were observed is in accordance with the propagating time from the expected source region to the location of the LSTIDs. One should remember that the AL index exhibited a clear signature of enhancement in west auroral 
electrojets around 02:20 UT. We assume that the AGW was induced during this event at nighttime auroral latitude, and it propagated poleward with speed of $190 \mathrm{~m} \mathrm{~s}^{-1}$ and $160 \mathrm{~m} \mathrm{~s}^{-1}$ equatorward, respectively. The AGW-induced LSTID, thus, would be detectable in daytime polar cap about $4 \mathrm{~h}$ later (roughly estimated by dividing the distance by the propagating speed), and one more hour later by ESR $42 \mathrm{~m}$ dish. This interval matches with the time when the LSTIDs were observed by ESR $42 \mathrm{~m}$ dish, which saw the first clear electron density perturbation around 08:00 UT. At the nightside, the equatorward waves could reach mid-latitude at least $2.6 \mathrm{~h}$ later. This time interval is roughly consistent with observations shown in Figs. 4 and 5 since clear positive TECP were detected around or later than 05:00 UT. Unfortunately, the IMAGE and POLAR satellites were not at the right position, providing little useful information about auroral activities during nighttime in Northern Hemisphere.

We are not able to deny the possibility that the daytime and nighttime LSTIDs were generated separately at different locations around nighttime auroral latitude. In addition to the accordance of their periods, however, one may also note that the phase velocities of the nighttime LSTID and the transpolar LSTID are comparable, which were evaluated at a similar distance away from their source regions in opposite directions. The similar characteristics of the daytime and nighttime LSTIDs suggest a close linkage between their driving forces at the source region. Considering that the source region must be elongated in east-west at nighttime auroral latitude, we would like to suggest that the daytime and nighttime LSTIDs are likely to have been launched from the same region, possibly at different parts of it.

\section{Summary}

We have presented observations of LSTIDs on both the dayside and nightside, which are likely to originate from the same source region. The source regions are expected to be elongated in east-west at nightside auroral latitude. The daytime mid-latitude LSTID seems to be a consequence of the transpolar AGW/TID reported by Cai et al. (2011), which must have been launched on the nightside during substorm activity and have propagated poleward from the source region. The poleward-moving waves cross the polar cap from nightside to dayside and then are detected consecutively by EISCAT/ESR radars (in polar region) and by ground-based GPS receiver chains (at mid-latitude) around geomagnetic local noon. During that period, the nighttime southwardmoving ionospheric disturbances are recorded by GPS receivers at North American sector (equatorward of the source region). Our results provide further experimental evidence to support the theoretical findings of Balthazor and Moffett (1999) that poleward-propagating LSTID could be selfconsistently driven at nighttime auroral latitude.
Acknowledgements. We are grateful to the IGS for providing GPS RINEX files used in present work. This work was supported by Natural Science Foundation of China (No. 40874079) and by Specialized Research Fund for Key Laboratory of Polar Science of the State Oceanic Administration (No. KP201002).

Topical Editor K. Kauristie thanks S. C. Buchert and one anonymous referee for their help in evaluating this paper.

\section{References}

Afraimovich, E. L., Kosogorov, E. A., Leonovich, L. A., Palamartchouk, K. S., Perevalova, N. P., and Pirog, O. M.: Determining parameters of large-scale traveling ionospheric disturbances of auroral origin using GPS-arrays, J. Atmos. Sol. Terr. Phys., 62, 553-565, 2000.

Balthazor, R. L. and Moffett, R. J.: Morphology of large-scale traveling atmospheric disturbances in the polar thermosphere, J. Geophys. Res., 104, 15-24, 1999.

Bowman, G. G. and Mortimer, I. K.: Some characteristics of large-scale travelling ionospheric disturbances and a relationship between the $\mathrm{F}_{2}$ layer height rises of these disturbances and equatorial pre-sunrise events, Ann. Geophys., 28, 1419-1430, doi:10.5194/angeo-28-1419-2010, 2010.

Cai, H. T., Yin, F., Ma, S. Y., and McCrea, I. W.: Observations of AGW/TID propagation across the polar cap: a case study, Ann. Geophys., 29, 1355-1363, doi:10.5194/angeo-291355-2011, 2011.

Davis, M. J.: On polar substorms as the source of large-scale traveling ionospheric disturbance, J. Geophys. Res., 76, 4525-4533, 1971.

Ding, F., Wan, W., Liu, L., Afraimovich, E. L., Voeykov, S. V., and Perevalova, N. P.: A statistical study of large-scale Traveling ionospheric disturbances observed by GPS TEC during major magnetic storms over the years 2003-2005, J. Geophys. Res., 113, A00A01, doi:10.1029/2008JA013037, 2008.

Francis, S. H.: Global propagations of atmospheric gravity waves: a review, J. Atmos. Sol. Terr. Phys., 37, 1011-1054, 1975.

Hajkowicz, L. A.: Global onset and propagation of large-scale travelling ionospheric disturbances as a result of the great storm of 13 March 1989, Planet. Space Sci., 39, 583-593, 1991.

Hernández-Pajares, M., Juan, J. M., and Sanz, J.: High resolution TEC monitoring method using permanent ground GPS receivers, Geophys. Res. Lett., 24, 1643-1646, 1997.

Hernández-Pajares, M., Juan, J. M., and Sanz, J.: Medium-scale traveling ionospheric disturbances affecting GPS measurements: Spatial and temporal analysis, J. Geophys. Res., 111, A07S11, doi:10.1029/2005JA011474, 2006.

Hines, C. O.: Internal tmospheric gravity waves at ionospheric waves at ionospheric heights, Can. J. Phys., 38, 1441-1481, 1960.

Hocke, K.: Tidal variations in the high-latitude E- and Fregion observed by EISCAT, Ann. Geophys., 14, 201-210, doi:10.1007/s00585-996-0201-9, 1996.

Hocke, K. and Schlegel, K.: A review of atmospheric gravity waves and travelling ionospheric disturbances: 1982-1995, Ann. Geophys., 14, 917-940, doi:10.1007/s00585-996-0917-6, 1996.

Hunsucker, R. D.: Atmospheric gravity waves generated in the high-latitude ionosphere: A review, Rev. Geophys., 20, 293-315, 1982. 
Ma, S. Y., Schlegel, K., and Xu, J. S.: Case studies of the propagation characteristics of auroral TIDS with EISCAT CP2 data using maximum entropy cross-spectral analysis, Ann. Geophys., 16, 161-167, doi:10.1007/s00585-998-0161-3, 1998.

Morgan, M. G.: Locating TID sources with a north-south chain of rapid-run ionosondes in western Quebec, Radio Sci., 18, 10661076, 1983.

Nicolls, M. J., Kelley, M. C., Coster, A. J., Gonzalez, S. A., and Makela, J. J.: Imaging the structure of a large-scale TID using ISR and TEC data, Geophys. Res. Lett., 31, L09812, doi:10.1029/2004GL019797, 2004.

Richmond, A. D.: Gravity wave generation, propagation and dissipation in the thermosphere, J. Geophys. Res., 83, 4131-4145, 1978.

Saito, A., Fukao, S., and Miyazaki, S.: High resolution mapping of TEC perturbations with the GSI GPS network over Japan, Geophys. Res. Lett., 25, 3079-3082, 1998.

Shiokawa, K., Ostuka, Y., Ogawa, T., Balan, N., Igarashi, K., Ridley, A. J., Knipp, D. J., Saito, A., and Yumoto, K.: A large-scale traveling ionospheric disturbance during the magnetic storm of 15 Septmeber 1999, J. Geophys. Res., 107, 1088, doi:10.1029/2001JA000245, 2002.
Shiokawa, K., Lu, G., Otsuka, Y., Ogawa, T., Yamamoto, M., Nishitani, N., and Sato, N.: Ground Observations and AMIE-TIEGCM modeling of a storm-time traveling ionospheric disturbance, J. Geophys. Res., 112, A05308, doi:10.1029/2006JA011772, 2007.

Tsugawa, T., Saito, A., Otsuka, Y., and Yamamoto, M.: Damping of large-scale traveling ionospheric disturbances detected with GPS networks during the geomagnetic storm, J. Geophys. Res., 108, 1127, doi:10.1029/2002JA009433, 2003.

Valladares, C. E., Villalobos, J., Hei, M. A., Sheehan, R., Basu, Su., MacKenzie, E., Doherty, P. H., and Rios, V. H.: Simultaneous observation of traveling ionospheric disturbances in the Northern and Southern Hemispheres, Ann. Geophys., 27, 1501-1508, doi:10.5194/angeo-27-1501-2009, 2009.

Williams, P. J. S., Virdi, T. S., Lewis, R. V., Lester, M., Rodger, A. S., McCrea, I. W., and Freeman, K. S. C.: Worldwide atmospheric gravity-wave study in the European sector 1985-1990, J. Atmos. Sol.-Terr. Phys., 55, 683-696, 1993. 